\title{
Impaired glucose homeostasis in Shb-/- mice
}

\author{
Björn Åkerblom, Sebastian Barg*, Gabriela Calounova*, Dariush Mokhtari, Leif Jansson \\ and Michael Welsh
}

Department of Medical Cell Biology, Uppsala University, PO Box 571, Husargatan 3, 75123 Uppsala, Sweden

(Correspondence should be addressed to M Welsh; Email: michael.welsh@mcb.uu.se)

*(S Barg and G Calounova contributed equally to this work)

\begin{abstract}
Src homology 2 domain-containing protein $\mathrm{B}(\mathrm{SHB})$ is an adapter protein involved in the regulation of $\beta$-cell and endothelial cell function. We have recently obtained the Shb knockout mouse, and consequently, the aim of this study was to assess the effect of Shb deletion upon $\beta$-cell function and blood glucose homeostasis. Shb $-/-$ mice display an elevated basal blood glucose concentration, and this increase is maintained during insulin challenge in insulin sensitivity tests. To assess glucose-induced insulin secretion, pancreata were perfused, and it was observed that $S h b-/-$ first phase insulin secretion was blunted during glucose stimulation. Gene expression of $S h b-/-$ islets shortly after isolation was altered, with increased pancreatic and duodenal homeobox gene-1 $(P d x 1)$ gene expression and reduced expression of Vegf- $A$. Islet culture normalized $P d x 1$ gene expression.
\end{abstract}

The microvascular density of the $S h b-/-$ islets was reduced, and islet capillary endothelial cell morphology was changed suggesting an altered microvascular function as a contributing cause to the impaired secretory activity. Capacitance measurements of depolarization-induced exocytosis indicate a direct effect on the exocytotic machinery, in particular a dramatic reduction in readily releasable granules, as responsible for the insulin-secretory defect operating in $S h b-/-$ islets. Shb $-/-$ mice exhibited no alteration of islet volume or $\beta$-cell area. In conclusion, loss of Shb impairs insulin secretion, alters islet microvascular morphology, and increases the basal blood glucose concentration. The impaired insulin secretory response is a plausible underlying cause of the metabolic impairment observed in this mutant mouse.

Journal of Endocrinology (2009) 203, 271-279

\section{Introduction}

The blood glucose level in the body is tightly regulated within narrow limits by several factors, of which the hormone insulin, produced by the $\beta$-cells in the islets of Langerhans, is the most pivotal. Interference with $\beta$-cell function by introducing mutations in genes coding for $\beta$-cell key proteins may cause impairment or loss of blood glucose homeostasis, as exemplified by the existence of mutations causing maturity onset diabetes of the young (MODY; Velho \& Robert 2002), and consequently, mutagenic strategies generate useful tools to elucidate mechanisms operating in human diabetes mellitus. $\beta$-Cell function is also dependent on the vasculature in the islets of Langerhans. $\beta$-Cells secrete high levels of vascular endothelial growth factor A to maintain their dense fenestrated capillary network. In return, endothelial cells provide the $\beta$-cells with basal lamina, which contain components that support insulin gene transcription and stimuli for replication (Johansson et al. 2006, Nikolova et al. 2006). Perturbation of $\beta$-cell-endothelial cell interaction or reduction in the islet vasculature may lead to an impaired $\beta$-cell function (Lammert et al. 2003, Brissova et al. 2006, Iwashita et al. 2007).
The adapter protein Src homology 2 domain-containing protein $\mathrm{B}(\mathrm{SHB})$, originally cloned from an insulin producing cell line (Welsh et al. 1994), is a ubiquitously expressed, versatile component in various signaling pathways associated with different receptor tyrosine kinases (Anneren et al. 2003). SHB has been shown to mediate cellular responses such as proliferation, differentiation, cell motility, or cell death, depending on the context studied. A $\beta$-cell-specific Shb transgenic mouse exhibits an increased $\beta$-cell mass and an accelerated return to normoglycemia following glucose challenge. Isolated transgenic islets also display an increased glucose-stimulated insulin secretion without showing an increased insulin content (Welsh et al. 1999). Furthermore, SHB is known to interact with insulin receptor substrates 1 and 2 following insulin stimulation of insulin producing cells, promoting focal adhesion kinase (FAK) association and phosphoinositide-3-kinase (PI3K) and extracellular signal regulated kinase (ERK) activation leading to pro-proliferative and anti-apoptotic signaling (Anneren \& Welsh 2002, Welsh et al. 2002). SHB also plays an important role in endothelial cells, where it associates with and relays signals from VEGFactivated VEGFR2, stimulating PI3K activity and FAK activation in concert with Src, promoting cytoskeletal 
rearrangements (Holmqvist et al. 2004). We have recently generated an Shb knockout mouse (Kriz et al. 2007). This mouse is viable on a mixed genetic background, but in several organs there are morphological aberrations observed in endothelial cells (Funa et al. 2009). This fact, together with the above-described reports indicating a role for SHB in $\beta$-cell function, motivated an investigation of blood glucose homeostasis in the Shb-/- mouse.

\section{Materials and Methods}

Animals

The Shb- / - mouse was previously generated in house (Kriz et al. 2007), and the Shb null allele is maintained on a mixed background of FVB/N, C57Bl/6, and 129/SvJ strains. The Shb null allele was not inherited according to the Mendelian genetics and thus an alternative strategy besides using littermates for generating $S h b+/+$ (wild-type) and Shb $-/-$ mice was adopted. Breeding pairs consisting of male and female wild-type or $S h b-/-$ mice were obtained from littermates and their offspring used in the experiments. Experiments were conducted with mice of 3-6 months of age, unless otherwise stated. Blood glucose tolerance tests and insulin tolerance tests were all initiated between 0815 and $0845 \mathrm{~h}$. The same person collected all blood samples for blood glucose determinations. The animal experiments were approved by the local animal ethics committee.

\section{Blood glucose tolerance test}

Male and female wild-type and Shb-/- mice, with free access to food, were given a single dose of $250 \mu \mathrm{l} 30 \% \mathrm{w} / \mathrm{v}$ D-glucose intravenously. Blood was withdrawn from the tail, $\sim 1 \mu \mathrm{l}$, and measured with Freestyle Mini System (Abbot, TheraSense Inc). Blood glucose was determined prior to injection and then at 10, 30, 60, and $120 \mathrm{~min}$ after injection. Number of mice: wild-type, $n=10 ; \operatorname{Sh} b-/-, n=16$.

\section{Blood sample collecting}

To determine the fasting blood glucose concentration, Shb - / - and wild-type mice were fasted over night. Blood was withdrawn from the tip of the tail and analyzed using the Freestyle Mini System. Number of mice: wild-type, $n=7 ; \operatorname{Sh} b-/-, n=7$.

For serum insulin analysis, randomly fed mice were bled retroorbitally by an experienced lab technician. Approximately, $0.5 \mathrm{ml}$ blood was withdrawn and allowed to clot at room temperature. Subsequently, samples were centrifuged, and serum was collected and frozen in $-20{ }^{\circ} \mathrm{C}$. Number of mice: wild-type, $n=10 ; \operatorname{Sh} b-/-, n=11$.

Blood sugar concentration in 9-month-old, randomly fed mice was measured between 0845 and $0920 \mathrm{~h}$ and analyzed with the Freestyle Mini System.
Insulin sensitivity test

Wild-type and $S h b-/-$ male mice were given an i.p. injection $(1.6 \mathrm{U} / \mathrm{kg}$ body weight) of the insulin analog NovoRapid (Novo Nordisk, Bagsværd, Denmark). Blood glucose was determined on blood samples from the tail, before injection and 15, 30, 45, 60, 75, 90, 120, and $180 \mathrm{~min}$ later using the Freestyle Mini System. The animals had free access to food before the insulin injection and were transferred to new cages without food during the measurements. Following the $120 \mathrm{~min}$ measurement, food was supplied. Number of mice: wild-type, $n=5$; Shb $-/-, n=5$.

Islet mass and $\beta$-cell area

To assess the islet mass, unfixed pancreata were weighed and then cut into parts and squashed between microscopy slides, and frozen in $-20^{\circ} \mathrm{C}$. Islet mass was determined as described earlier (Jansson \& Hellerstrom 1981). In brief, when thawed in room temperature, islets were clearly distinct in darkfield illumination from the exocrine part of the pancreas. The proportion of islets to total pancreas was determined using a microscope with a grid ocular and point counting at $24 \times$ magnification. Islet mass was assessed in five wild-type and five $S h b-/-3$-month-old mice. The relative $\beta$-cell area of seven wild-type and six Shb-/- 7-11-month-old mice was determined by insulin staining and computer-assisted morphometry on formalin-fixed, paraffin-embedded pancreata as described in Akerblom et al. (2007), with eight pancreas sections measured per animal.

\section{Perfusion of pancreas}

Male wild-type and $S h b-/-$ mice were anesthetized with an i.p. injection of Avertin, $0.02 \mathrm{ml} / \mathrm{g}$ body weight $(2.5 \%$ (vol/vol) saline solution) of $10 \mathrm{~g}$ of $97 \%$ 2,2,2-tribromoethanol (Sigma-Aldrich) in $10 \mathrm{ml}$ of 2-methyl-2-butanol (Kemila, Stockholm, Sweden). Pancreas and duodenum were isolated as previously described (Jansson 1986), in short: a catheter was inserted in the abdominal aorta, then all vessels except those supplying the pancreas were ligated. The portal vein was then severed, and another catheter was inserted into the vein. The pancreas preparation was placed in a chamber with constant temperature and humidity, and subsequently perfused with Krebs-Ringer-bicarbonate-Hepes buffer (KRBH) supplemented with 2\% dextran 70 (GE Healthcare, Uppsala, Sweden) and 2\% BSA fraction V (MP Biomedicals, Eschwege, Germany). Perfusion media and time intervals were in the following order: $2 \cdot 8 / \mathrm{mM}$ D-glucose in $\mathrm{KRBH}$ for $15 \mathrm{~min}, 16.7 / \mathrm{mM} \mathrm{D}$-glucose in $\mathrm{KRBH}$ for $20 \mathrm{~min}$, $2 \cdot 8 / \mathrm{mM}$ D-glucose in $\mathrm{KRBH}$ for $15 \mathrm{~min}, 10 / \mathrm{mM}$ arginine and $5 / \mathrm{mM}$ D-glucose for $10 \mathrm{~min}$, and $2 \cdot 8 / \mathrm{mM}$ D-glucose in $\mathrm{KRBH}$ for $15 \mathrm{~min}$. Perfusion was performed at a constant rate of $1 \mathrm{ml} / \mathrm{min}$, with perfusion media kept at $37^{\circ} \mathrm{C}$ and 
continuously gassed with $\mathrm{O}_{2} / \mathrm{CO}_{2}$ (95:5). Perfusion medium was collected and stored at $-20{ }^{\circ} \mathrm{C}$ prior to analysis of insulin content. Insulin content was measured by ELISA (Rat insulin ELISA 10-1124, Mercodia, Uppsala, Sweden), according to the manufacturer's instructions. Number of mice: wild-type, $n=4 ; S h b-/-, n=5$. To calculate total insulin release, the area under curve for each individual perfused pancreas was estimated.

\section{Pancreatic insulin content}

For the determination of the pancreatic insulin content, a piece of pancreas about 15-20 mg was taken from the tail of the pancreas. This piece was put into $1 \mathrm{ml}$ acidic ethanol $(0 \cdot 18 / \mathrm{M} \mathrm{HCl}-70 \%$ ethanol), and then after $30 \mathrm{~min}$, sonicated while kept on ice. The sonicates were kept in $+4{ }^{\circ} \mathrm{C}$ overnight and, the following day, insulin content was determined by ELISA. Number of mice 9-12 weeks old: wild-type, $n=5$ mice, $S h b-/-, n=5$ mice.

\section{Islet isolation and islet insulin release}

Animals were killed, and pancreata were removed and put into Hanks' solution (SVA, Uppsala, Sweden). Each pancreas was cut into pieces with scissors and subjected to a $3 \mathrm{ml}$ collagenase solution ( $1 \mathrm{mg} / \mathrm{ml}$ in Hanks', Sigma-Aldrich) digestion for $20 \mathrm{~min}$ at $37^{\circ} \mathrm{C}$, on a shaking water bath, then washed twice with wash buffer (Ringer-acetate, FreseniusKabi, Uppsala, Sweden, supplemented with $4.5 / \mathrm{mM}$ $\mathrm{NaHCO}_{3}, 2 \cdot 5 / \mathrm{mM}$ glucose and penicillin-streptomycin), and suspended in Hanks'. Islets were hand-picked under a stereomicroscope and cultured in RPMI 1640 supplemented with 10\% fetal bovine serum (Sigma-Aldrich), L-glutamine (Sigma-Aldrich), and penicillin-streptomycin, for 3-4 days before experiments. For glucose-stimulated insulin release, doublets of ten islets each from wild-type or $\mathrm{Shb}-/-$ mice were transferred to $\mathrm{KRBH}$ supplemented with $0 \cdot 2 \% \mathrm{BSA}$ and $1.7 \mathrm{mM}$ glucose, and incubated in $37^{\circ} \mathrm{C}, 95 \% \mathrm{O}_{2}, 5 \% \mathrm{CO}_{2}$ atmosphere for $60 \mathrm{~min}$. The islet medium was then collected and replaced with $\mathrm{KRBH}, 0 \cdot 2 \%$ BSA, $16 \cdot 7 \mathrm{mM}$ glucose. Islets were incubated for another $60 \mathrm{~min}$, after that medium and islets were separately collected. Islets were transferred to $200 \mu \mathrm{l}$ deionized water and sonicated. Totally $50 \mu \mathrm{l}$ of the islet homogenate was mixed with $125 \mu \mathrm{l}$ acid-ethanol $(0 \cdot 18 \mathrm{M}$ $\mathrm{HCl}$ in $95 \%$ (vol/vol) ethanol), for determination of insulin content by ELISA (Rat insulin ELISA, Mercodia). The rest of the islet homogenate was used for DNA measurements by fluorophotometry (PicoGreen dsDNA Quantitation kit; Molecular Probes, Eugene, OR, USA).

For high $\mathrm{K}^{+}$-induced insulin release, triplets of ten islets each from wild-type or $\mathrm{Shb}-/$ - mice were preincubated for $1 \mathrm{~h}$ in $\mathrm{KRBH} 0 \cdot 2 \%$ BSA, $3 \cdot 3 \mathrm{mM}$ glucose in $37^{\circ} \mathrm{C}, 95 \% \mathrm{O}_{2}$, $5 \% \mathrm{CO}_{2}$ atmosphere. The islet media were then changed, and islets were incubated for $30 \mathrm{~min}$. Subsequently, the media were collected and replaced with high $\mathrm{K}^{+} \mathrm{KRBH}$ $\left(\left[\mathrm{K}^{+}\right] \quad 34.7 \mathrm{mM},\left[\mathrm{Na}^{+}\right] \quad 113.5 \mathrm{mM}\right) \quad 0 \cdot 2 \%$ BSA, $3.3 \mathrm{mM}$ glucose, and islets were incubated for another $30 \mathrm{~min}$. After that, medium and islets were collected and treated as described above.

\section{Capacitance measurements}

Single-cell measurements of exocytosis were performed in isolated intact islets by patch clamp in the whole-cell configuration using an EPC-9 amplifier controlled by Pulse software (both HEKA Elektronik, Lambrecht, Germany). The intracellular solution consisted of (in $\mathrm{mM}$ ) 125 Cs-glutamate, $10 \mathrm{NaCl}, 1 \mathrm{MgCl}_{2}, 3$ ATP-Mg, 0.1 cAMP,

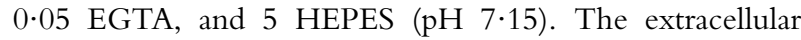
solution (EC) was (in $\mathrm{mM}$ ) $138 \mathrm{NaCl}, 5 \cdot 6 \mathrm{KCl}, 1 \cdot 2 \mathrm{MgCl}_{2}$, $2 \cdot 6 \mathrm{CaCl}_{2}, 3$ D-glucose, and $10 \mathrm{mM}$ HEPES (pH 7.40) and held at $\sim 32{ }^{\circ} \mathrm{C}$. Capacitance was measured using $1000 \mathrm{~Hz}$, $20 \mathrm{mV}$ sine waves around $-70 \mathrm{mV}$ and offline calculation in Pulse. $\beta$-Cells on the surface of intact islets were identified by their electrophysiological properties (Gopel et al. 1999, Barg et al. 2000).

\section{$R N A$ isolation and quantitative real-time RT-PCR}

Thirty freshly isolated islets/sample were hand-picked and briefly washed in PBS, then lysed and homogenized in RNA preparation lysis buffer. Total RNA was prepared by using the RNeasy mini kit (Qiagen) with on-column DNase digestion with RNase-Free DNase set (Qiagen), according to the manufacturer's descriptions. One-step quantitative real-time RT-PCR was performed with QuantiTect SYBR Green RT-PCR-kit (Qiagen) on a LightCycler real-time PCR machine (Roche Diagnostics). The following primer sequences were used: annealing temperature $55^{\circ} \mathrm{C}$ : $\beta$-actin, forward GCTCTGGCTCCTAGCACC, reverse CCACCGATC CACACAGAGTACTTG; hepatocyte nuclear factor $(H n f)-1 \alpha$, forward GATGAG CTGCCAACTAAGAAGG, reverse TTGTAGACACGCACCTCCGTGA; $H n f-3 \beta$ (Foxa2), forward AAGCGAGCTAAAGGGAGCA CCT, reverse GCTCGGACGACATGAGGTTGTT; annealing temperature $57^{\circ} \mathrm{C}$ : mouse insulin, forward AACAGCATCTTTGTGGTCCC, reverse CACTTGTGGGTCCTCCACTT; pancreatic and duodenal homeobox gene-1 (Pdx1) (NM_008814; TIB MOLBIOL, Berlin, Germany), glucose transporter 2 (Glut2) (cat\#. PPM04167A, Tebu-Bio, Roskilde, Denmark), glucokinase (Gck) (NM_010292, PPM05095A, Tebu-Bio). Annealing temperature $60^{\circ}$ : Vegfa, forward AAGGAGAGCAGAAGTCCCATGA, reverse CTCAATTGGACGGCAGTAGCT; Vegfr2, forward ACAGACCCGGCCAAACAA, reverse TTCCCCCCTGGAAATCCTC; CD31, forward TACTGCAGGCATCGGCAAA, reverse GCATTTCGCACACCTGGAT.

Reverse transcription and cycling conditions were performed following the standard recommendations of the kit. Cycle threshold $\left(C_{\mathrm{T}}\right)$ values were determined with the 
LightCycler Software v3.5. Gene expressing was normalized by subtracting the corresponding $\beta$-actin $C_{\mathrm{T}}$ value. Statistical comparisons were made on normalized $C_{\mathrm{T}}$ values.

\section{Transmission electron microscopy}

For islet endothelial cell morphology and islet microvascular density, pancreata from 7- to 11-month-old wild-type and Shb $-/-$ mice were cut into small pieces and fixed in $2 \%$ glutaraldehyde and $1 \%$ paraformaldehyde. Tissue preparation for electron microscopy has been described previously (Funa et al. 2009).

\section{Functional islet capillary proportion}

Mice were injected through the tail vein with $50 \mu \mathrm{g}$ FITClabeled Tomato lectin (\# FL-1171, Vector Laboratories Inc., Burlingame, CA, USA) and killed after 3 min. Pancreas was removed and submerged in Tissue Tek O.C.T compound and frozen on a metal cylinder embedded in dry ice. Pancreata were sectioned in a cryostat, and $7 \mu \mathrm{m}$ sections were mounted onto SuperFrost Plus microscope slides (Menzel-Gläser, Braunschweig, Germany). To visualize endothelial cells, sections were stained for the endothelial cell marker, cluster of differentiation 31 (CD31). In brief, sections were fixed for $10 \mathrm{~min}$ in cold methanol in $-20{ }^{\circ} \mathrm{C}$, then washed in PBS, blocked $1 \mathrm{~h} \mathrm{RT}$ in $2 \% \mathrm{BSA}$ in PBS, $1^{\circ}$ antibody: 1:500 $1 \mathrm{~h}$ $\mathrm{RT}$ rat anti-mouse CD31 (www.bdbiosciences.com) in $2 \%$ BSA in PBS, washed in PBS, $2^{\circ}$ antibody: 1:500 $1 \mathrm{~h}$ RT Alexa Fluor 594 goat anti-rat IgG $(\mathrm{H}+\mathrm{L})$ (Invitrogen, Molecular Probes) in 2\% BSA in PBS, washed again in PBS, and finally mounted using Vectashield Hard Set mounting medium with DAPI (Vector Laboratories Inc). Photos of islets were taken with a Nikon Eclipse TE2000-U fluorescence inverted microscope, with a Nikon D Eclipse C1 camera and Nikon ACT-1C for DXM1200-C v1.02.10 software, using the $40 \times$ objective. The number of tomato lectin and CD31 positive microvessels were determined on blinded photos for five islets/pancreas. Number of mice: wild-type, $n=3$; Shb $-/-, n=3$.

\section{Statistical analysis}

Student's $t$-test was used for pairwise comparisons of normal distributed data, and the Mann-Whitney $U$ test was used for pairwise comparisons of nonparametric data. Values displayed in figures and text are means \pm s.E.M. Statistical analyses were done using SigmaStat (SPSS Inc., Chicago, IL, USA), and $P$ values $<0.05$ were considered significant.

\section{Results}

\section{Glucose homeostasis}

To assess glucose homeostasis, randomly fed wild-type or Shb - / - mice 3-6 months old were subjected to an i.v. blood glucose tolerance test. There were no differences in the blood glucose concentrations between wild-type and Shb $-/-$ mice at 10,30 , or $60 \mathrm{~min}$ after injection, although there appeared to be a trend to an elevated glucose concentration at $60 \mathrm{~min}(P=0 \cdot 054$; Fig. 1A). The blood glucose values at 0 and $120 \mathrm{~min}$ were significantly elevated in the $S h b-/-$ mice (Table 1) compared with controls. To exclude the possibility that the elevated blood glucose reflected an altered food intake in the $S h b-/-$ mice, wildtype and $S h b-/-$ mice were fasted over night and the blood glucose concentration was measured in the following morning. The fasting blood glucose concentration in the Shb - / - mouse was elevated akin to that in the randomly fed condition (Table 1). The basal blood glucose concentration was increased similarly in mice 9 months of age as in the younger mice (Table 1), suggesting that the effect on blood glucose is age independent. The elevated blood glucose concentration was not a consequence of an altered systemic insulin concentration, since no differences in the serum insulin concentration could be assessed between randomly fed wild-type and $S h b-/-$ mice (Table 1$)$.
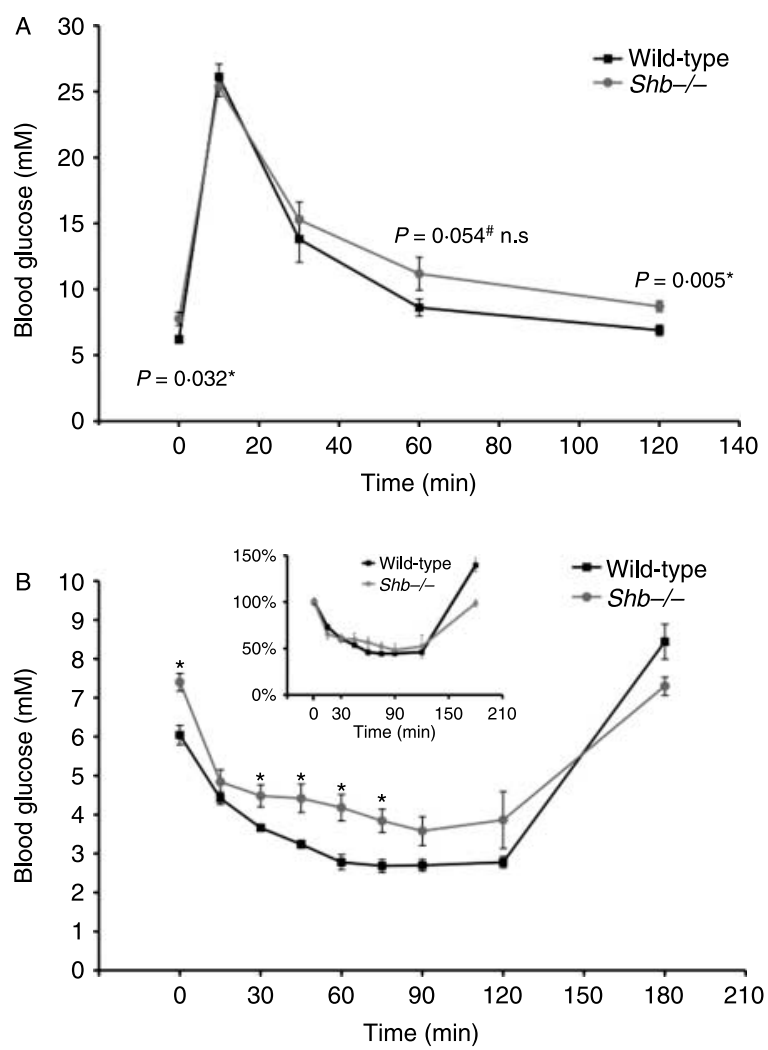

Figure 1 (A) Blood glucose tolerance test of $S h b-/-$ mice. Wild-type, $n=10 ; S h b-/-, n=16$. Comparisons made with: *Student's t-test, "Mann-Whitney $U$ test. (B) Insulin sensitivity test of Shb $-1-$ mice. Inset shows blood glucose concentrations in \% of 0 min values. Wild-type, $n=5$ mice; $S h b-/-, n=5$ mice. Student's $t$-test was used for comparisons; ${ }^{*}$ Denotes a $P$ value $<0 \cdot 05$. 
Table 1 Blood glucose concentration, serum insulin concentration, islet volume, $\beta$-cell area, pancreatic insulin content, and microvascular density of $S h b-/-$ mice. Values are mean \pm S.E.M.

\section{BGTT $0 \mathrm{~min} / \mathrm{mM}$}

BGTT $120 \mathrm{~min} / \mathrm{mM}$

Fasting blood glucose per $\mathrm{mM}$

Insulin sensitivity test $0 \mathrm{~min} / \mathrm{mM}$

Blood glucose at 9 months $/ \mathrm{mM}$

Serum insulin $\mathrm{ng} / \mathrm{ml}$

Islet mass mg at 3 months

Animal weight at 3 months

Pancreas weight at 3 months

$\beta$-Cell area $\%$ at $7-11$ months

Pancreatic insulin content $\mu \mathrm{g} / \mathrm{mg}$

CD31 positive microvascular density (number $\times 100 / \mathrm{mm}^{2}$ )

Tomato lectin positive structures (number $\times 100 / \mathrm{mm}^{2}$ )

Tomato lectin/CD31 positive vessels \%

\begin{tabular}{|c|c|c|}
\hline Wild-type & $S h b-/-$ & $P$ value \\
\hline $6 \cdot 2 \pm 0 \cdot 30(10)$ & $7 \cdot 8 \pm 0 \cdot 51(16)$ & 0.032 \\
\hline $6 \cdot 9 \pm 0 \cdot 40(10)$ & $8 \cdot 7 \pm 0 \cdot 39(16)$ & 0.005 \\
\hline $2 \cdot 9 \pm 0 \cdot 21(7)$ & $3 \cdot 8 \pm 0 \cdot 36(7)$ & $0 \cdot 038$ \\
\hline $6 \cdot 0 \pm 0 \cdot 25(5)$ & $7 \cdot 4 \pm 0 \cdot 23$ & $0 \cdot 004$ \\
\hline $6 \cdot 2 \pm 0 \cdot 29(6)$ & $7 \cdot 3 \pm 0 \cdot 24(8)$ & $0 \cdot 015$ \\
\hline $1 \cdot 0 \pm 0 \cdot 16(10)$ & $1 \cdot 3 \pm 0 \cdot 13(11)$ & $0 \cdot 13$ \\
\hline $3 \cdot 8 \pm 0 \cdot 4(5)$ & $3 \cdot 7 \pm 0 \cdot 4(5)$ & $0 \cdot 92$ \\
\hline $27 \cdot 9 \pm 0 \cdot 8(5)$ & $29 \cdot 7 \pm 1 \cdot 9(5)$ & $0 \cdot 39$ \\
\hline $0 \cdot 34 \pm 0 \cdot 02(5)$ & $0 \cdot 33 \pm 0 \cdot 01$ & $0 \cdot 65$ \\
\hline $0 \cdot 70 \pm 0 \cdot 09(7)$ & $0 \cdot 79 \pm 0 \cdot 11(6)$ & $0 \cdot 58$ \\
\hline $0 \cdot 26 \pm 0 \cdot 028(5)$ & $0 \cdot 29 \pm 0 \cdot 044(5)$ & $0 \cdot 63$ \\
\hline $26 \pm 1 \cdot 6(3)$ & $21 \pm 0 \cdot 8(3)$ & $0 \cdot 04$ \\
\hline $19 \pm 1 \cdot 5(3)$ & $15 \pm 0.08(3)$ & $0 \cdot 04$ \\
\hline $74 \pm 3(3)$ & $76 \pm 1(3)$ & $0 \cdot 47$ \\
\hline
\end{tabular}

(n) number of animals. Comparisons with Student's $t$-test. BGTT, blood glucose tolerance test.

The possibility that these abnormalities in Shb-/- blood glucose homeostasis reflected reduced peripheral insulin sensitivity was examined by performing insulin sensitivity tests (Fig. 1B). Both wild-type and Shb-/- mice responded to an insulin administration by reducing their blood glucose concentrations, and the reduction in blood glucose from the starting value was identical in both groups of mice (see inset in Fig. 1B). As previously seen, the basal blood glucose concentration was elevated in randomly fed $S h b-/-$ mice compared with wild-type mice (Table 1), and for this reason, the Shb-/- values were higher at 30, 45, 60, $75 \mathrm{~min}$ after insulin administration when compared with wild-type mice $(P=0.024,0.014,0.007,0.009$ respectively). Thus, Shb-/- mice displayed also in these experiments an increased basal blood glucose concentration that decreased upon insulin challenge to a similar degree as that of wild-type controls. To address whether the observed alteration in the blood sugar concentration could be a cause of a decreased number of $\beta$-cells, islet mass was investigated and, in addition, $\beta$-cell area was determined in 7-11-month-old Shb- /- and wild-type mice. However, these investigations revealed no differences between the two genotypes (Table 1).

In summary, the results demonstrate an increased blood glucose concentration in the Shb gene knockout mouse without any effects on insulin sensitivity or $\beta$-cell area.

\section{Perfusion of pancreatic explants}

To test the insulin secretory function of the $S h b-/-$ pancreas, pancreata from $S h b-/-$ and wild-type mice were isolated and perfused with low glucose, high glucose, and with arginine-glucose (Fig. 2A). Insulin secretion during initial low glucose perfusion was elevated in $S h b-/-$ pancreata $0 \cdot 90 \pm 0 \cdot 10$ versus wild-type $0 \cdot 54 \pm 0 \cdot 08 \mathrm{ng} / \mathrm{ml}$ per $\min (P=0 \cdot 028)$. $S h b-/-$ pancreata displayed a blunted first response to high glucose peaking at $31 \pm 6.8$ versus wildtype $66 \pm 5 \cdot 4 \mathrm{ng} / \mathrm{ml}$ per $\min (P=0 \cdot 005)$. The second phase response also showed a reduced insulin secretion when compared with the wild-type, $30 \mathrm{~min}$ value: $\mathrm{Shb}-/-$ $4 \cdot 0 \pm 0 \cdot 85$ versus wild-type $7 \cdot 1 \pm 0 \cdot 71 \mathrm{ng} / \mathrm{ml}$ per $\min$ $(P=0 \cdot 03)$. The response to arginine by $S h b-/-$ pancreata exhibited a similar blunted pattern as the response to high glucose, although it did not reach statistical significance (52 min value $P=0 \cdot 11$ ).
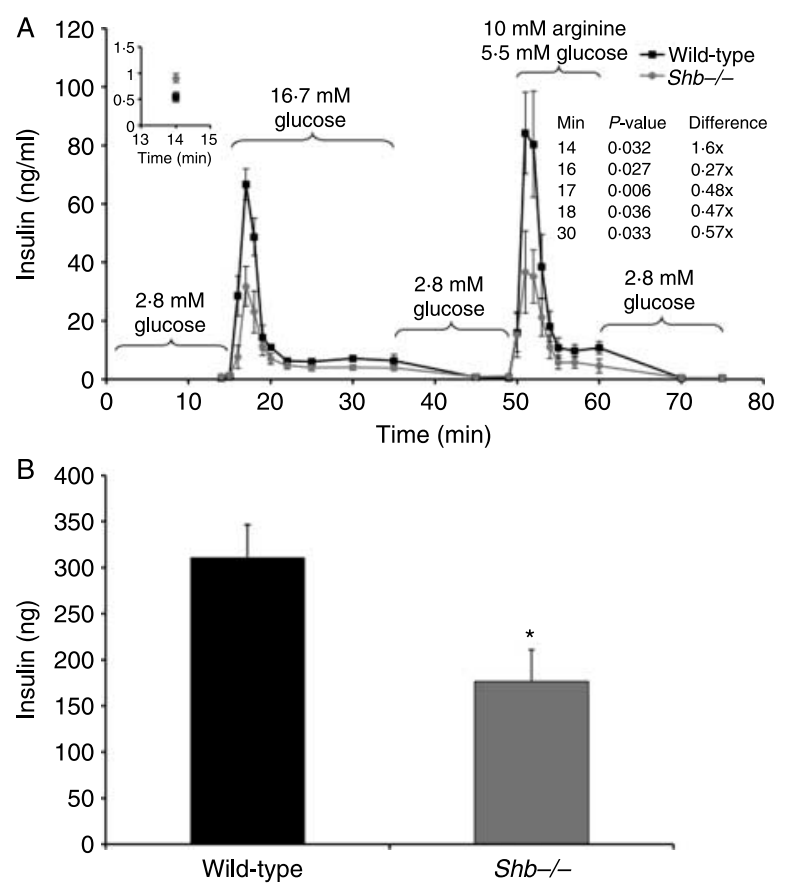

Figure 2 (A) Perfusion of pancreatic explants. Wild-type, $n=4$; Shb $-/-, n=5$. Student's $t$-test was used for comparisons. (B) Total insulin released during stimulation with high glucose. Wild-type, $n=4$ pancreata; $S h b-/-n=5$ pancreata. Student's $t$-test was used for comparisons. 
Total amount of insulin released by $S h b-/-$ pancreata during the first and second phase response to high glucose stimulation was reduced by $44 \%$ compared with wild-type animals (Fig. 2B).

To address whether the reduced insulin secretion was caused by reduced pancreatic insulin content in $S h b-/-$ pancreata, the pancreatic insulin contents of wild-type and Shb - / - mice were assessed. However, there was no difference in insulin content between wild-type and Shb $-/-$ pancreata (Table 1).

\section{Gene expression in freshly isolated islets}

Since the insulin secretion of the $S h b-/-$ pancreas in the pancreas perfusion experiment was perturbed, it was of interest to assess whether $S h b$ gene knockout affected the expression of genes important in maintaining $\beta$-cell function.

Gene expression of $P d x 1$, insulin, Glut2, and Gck was determined by quantitative real-time RT-PCR. (Fig. 3) Analysis revealed a fivefold upregulation of $P d x 1 \mathrm{mRNA}$, while no difference in the expression of genes downstream of $P d x 1$ (insulin, Glut2, Gck) was observed. The elevated expression of $P d x 1$ diminished after culture of the islets (data not shown). Expression of the transcription factors Hnf $1 a$ and Hnf-3 $\beta$ (listed as Foxa2 in the MGI Database), which regulate $P d x 1$ transcription (Gerrish et al. 2001, Lee et al. 2002), did not differ from that of wild-type islets.

Disturbed $\beta$-cell-capillary interactions may impair $\beta$-cell function (Lammert et al. 2003, Brissova et al. 2006, Nikolova et al. 2006, Iwashita et al. 2007). Therefore, expression of Vegfa and endothelial cell markers Vegfr2 and CD31 were investigated. Expression of Vegfr 2 and CD31 in Shb-/islets was not different compared with wild-type islets, although Vegfa expression was reduced by $50 \%$.

\section{Islet endothelial cell morphology and islet microvascular density}

The reduction of Vegfa expression in $S h b-/-$ islets prompted us to investigate the islet vasculature and endothelial cell morphology by transmission electron

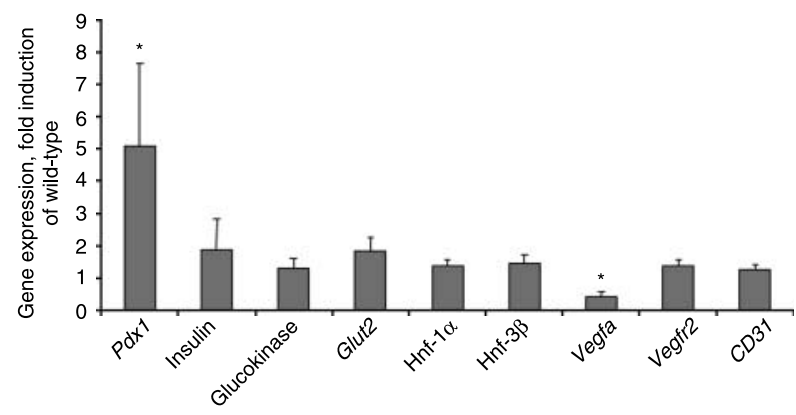

Figure 3 Gene expression in $S h b-/-$ islets displayed as fold induction compared with wild-type gene expression. Wild-type, $n=5$ islet preparations from five mice; Shb-/-, $n=5$. Student's paired $t$-test was used for comparisons. microscopy (TEM). The endothelial cytoplasm was found to be thickened in Shb-/- islet capillaries (Fig. 4). In addition, the TEM sections examined showed a reduced density of capillaries in Shb-/- islets (Fig. 4). Capillary fenestrations were not affected to any major extent by SHB deficiency.

Attempts to directly determine islet blood flow failed since the mice on the mixed genetic background (FVB/C57Bl6/129Sv) demonstrated a significant drop in blood pressure during anesthesia. For this reason, the proportion of functional islet capillaries was assessed by relative tomato lectin binding, 3 min after injection in the tail vein of nonanesthetized mice. This was found to be virtually identical in wild-type and $S h b-/-$ islets (Table 1). Since the TEM sections had shown reduced capillary density in Shb - / - islets, we conclude that the functional capacity of the islet vasculature was reduced in the $S h b$ knockout. Indeed, we also found that the number of tomato lectin positive capillaries per area unit was reduced in the Shb knockout islets (Table 1).
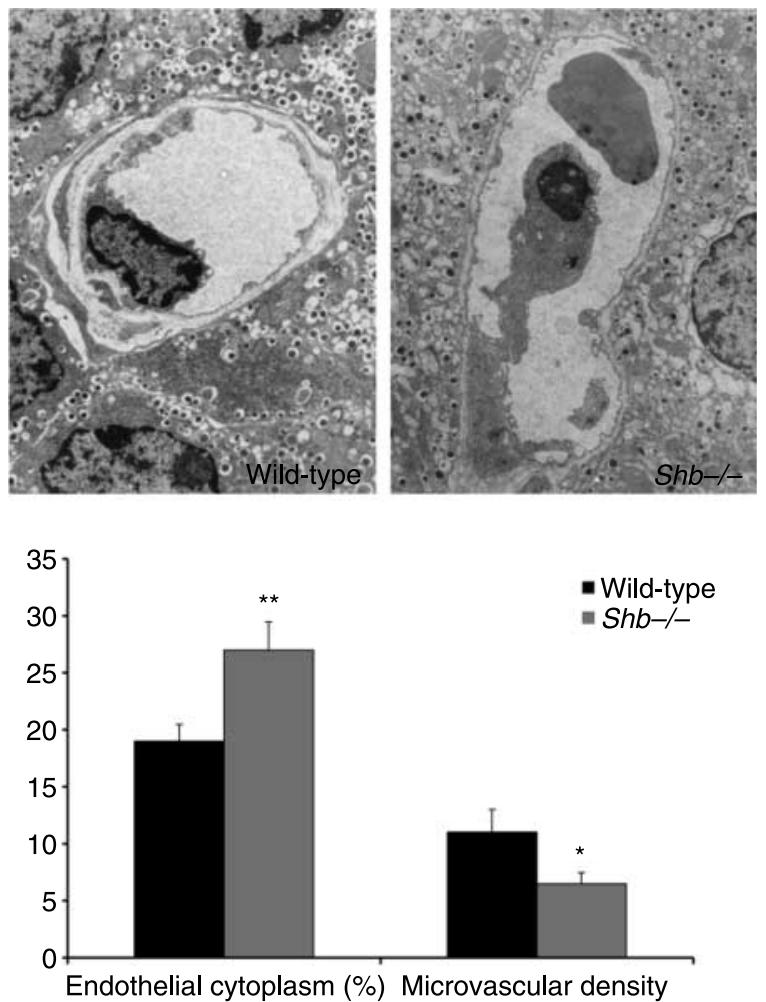

Figure 4 Islet microvasculature in 7-11-month-old mice. Ultrastructure (original magnification $5000 \times$, micrographs below are blowups of this magnification) and quantification of percent cytoplasm of total capillary area (including lumen) and number of capillaries $\times 10^{-2} / \mathrm{mm}^{2}$ are given in means \pm S.E.M. for $8-15$ observations (each observation is one endothelial cell for quantification of percent cytoplasm, or one islet for determination of microvascular density). The pictures for quantification were from four wild-type and five $S h b-/-$ mice. Student's $t$-test was used for comparisons; * and ${ }^{* *}$ denote $P<0.05$ and $P<0.01$ respectively. 
Islet insulin release and patch clamp experiments

Although the observed alterations in the islet vasculature may explain the reduced glucose-stimulated insulin secretion observed in the pancreatic explants, this could also be caused by impaired $\beta$-cell function in $S h b-/-$ mice. To address islet insulin secretion in the absence of functional blood vessels, we performed high glucose incubation experiments on isolated islets. Shb $-/-$ islets displayed reduced glucosestimulated insulin secretion in comparison with wild-type islets (Fig. 5). The wild-type and $\mathrm{Shb}-/-$ islet DNA or insulin contents were similar under the conditions examined (Mokhtari et al. 2009). To assess the post-K $\mathrm{K}_{\mathrm{ATP}}$-channel secretory functionality of $S h b-/-\beta$-cells, i.e. in absence of metabolic stimulus, islet insulin secretion was induced by incubation in high $\left[\mathrm{K}^{+}\right]$medium. Shb $-/-$islets exhibited reduced high $\mathrm{K}^{+}$-induced insulin release (Fig. 5), suggesting a post- $\mathrm{K}_{\mathrm{ATP}}$-channel defect operating in these $\beta$-cells.

In order to characterize the decreased insulin secretion of $\mathrm{Sh} b-/-$ islets in more detail, we monitored $\beta$-cell exocytosis with whole-cell membrane capacitance measurements. Exocytosis was elicited by a train $(1 / \mathrm{s})$ of ten voltage clamp depolarizations from -70 to $0 \mathrm{mV}$, each lasting $500 \mathrm{~ms}$ (Fig. 6A, top). The first depolarization elicited a capacitance increase of $160 \pm 51 \mathrm{fF}$ in control, about eightfold more than the $22 \pm 20 \mathrm{fF}$ in $S h b-/-$ islets. This indicates that the readily releasable pool (RRP) of granules is greatly reduced in the Shb knockout. Subsequent depolarizations likewise evoked larger increases in the control than in $\mathrm{Shb}-/-$, but the difference faded towards the end of the stimulation protocol. The summed response during depolarizations 3-10 was $253 \pm 41 \mathrm{fF}$ in control, still about double the value observed in the knockout (KO), $121 \pm 45 \mathrm{fF}$ (Fig. 6B). These differences in exocytosis are unlikely due to increased influx

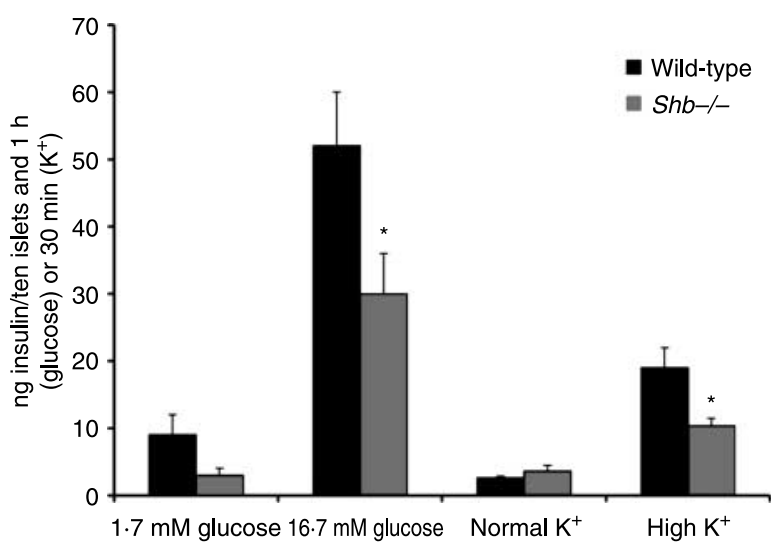

Figure 5 Glucose and $\mathrm{K}^{+}$induced islet insulin release. For glucose induced insulin release, means \pm S.E.M. are given for 11-14 determinations. For $\mathrm{K}^{+}$induced insulin release, means \pm s.E.M. are given for 12-15 determinations. The islet insulin contents after the high $\mathrm{K}^{+}$insulin secretion period were $751 \pm 165$ and 660 $\pm 110 \mathrm{ng} / 10$ islets for the wild-type and $S h b-/-$ islets respectively. *Indicates $P<0.05$ by Student's $t$-test, in comparison with corresponding wild-type islets.
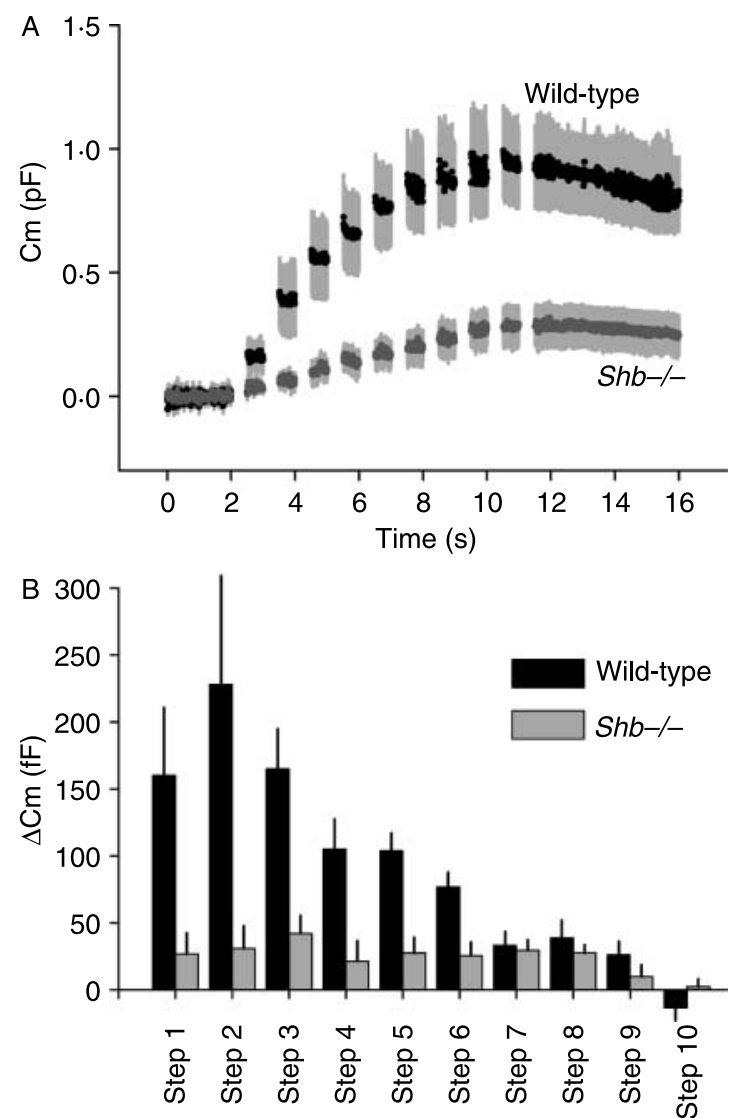

Figure 6 Capacitance measurements on $\beta$-cells within intact islets. (A) Capacitance recordings during a train of $10 \times 500 \mathrm{~ms}$ depolarizations at $1 \mathrm{~Hz}$ and beginning at $t=2 \mathrm{~s}$. Traces are averages from eight wild-type cells (black) and 11 Shb-/- cells (dark gray), with S.E.M. shown in light gray. (B) Capacitance increases for each depolarization for wild-type (black) and knockout (gray). Same data as in (A). The differences in steps $1-6$ were significant $(P<0 \cdot 05$ or better).

through voltage-gated $\mathrm{Ca}^{2+}$ channels, since both the charge and peaks of the associated $\mathrm{Ca}^{2+}$ currents were similar in the two groups $(13 \cdot 2 \pm 4 \cdot 0 \mathrm{pC}$ vs $9 \cdot 7 \pm 2 \cdot 7 \mathrm{pC}$ and $52 \pm 15 \mathrm{pA}$ vs $58 \pm 17 \mathrm{pA}$ in control and knockout respectively). Cells from both groups of animals had about the same initial size (9.2 $\pm 0.7 \mathrm{pF}$ in wild-type versus $9.1 \pm 0.4 \mathrm{pF}$ in the knockout). In summary, $\beta$-cells from $S h b-/-$ mice have a dramatically reduced RRP and a somewhat decreased rate at which granules are supplied to this pool.

\section{Discussion}

The present study was conducted in order to characterize glucose homeostasis in mice deficient in SHB. A transgenic mouse overexpressing $S h b$ in $\beta$-cells under the control of the rat insulin promoter displayed improved glucose tolerance and an increased $\beta$-cell mass. Mice deficient in SHB exhibit 
impaired glucose homeostasis, but their $\beta$-cell mass is normal. Thus, SHB is not likely required for maintenance of the $\beta$-cell mass or for $\beta$-cell differentiation.

Although SHB-deficient mice responded well to a glucose challenge, the blood glucose concentration was somewhat elevated prior to and $2 \mathrm{~h}$ after challenge. Likewise, the fasting blood glucose concentration was similarly increased. In contrast, the serum insulin concentration in randomly fed mice was normal and SHB-deficient mice responded to an insulin analog in manner similar to wild-type, although the difference in the blood glucose concentration remained. This suggests that insulin sensitivity in main insulin-sensitive tissues, skeletal muscles, and adipose tissue is not impaired to any major extent by SHB deficiency. Rather, it seems that a primary $\beta$-cell defect with release of less insulin in response to glucose is a more likely explanation for the impaired glucose homeostasis. Indeed, the pancreas perfusion experiments revealed an impaired glucose-stimulated insulin secretory response in $S h b-/-$ pancreata, exhibiting a blunted first phase response and decreased total amount of insulin secreted, while the pancreatic insulin content was normal. The findings do not rule out increased hepatic output of glucose as a cause of the elevated blood glucose concentration. However, gene expression analysis of three enzymes involved in hepatic glucose output (phosphoenolpyruvate carboxykinase 1 , fructose $1 \cdot 6$-bisphosphatase, and glucose-6-phosphatase) revealed no differences in the expression of these between $S h b-/-$ and wild-type livers (results not shown), leaving this issue undecided.

The cause of the reduced glucose-stimulated insulin secretion remains unresolved. The insulin secretory data in response to both high $\mathrm{K}^{+}$-depolarization and the patch clamp experiments suggest a direct effect on the secretory machinery. This defect appears to greatly reduce the size of the RRP of granules. There is good evidence that first phase insulin secretion represents exocytosis of RRP. These granules are docked just beneath of membrane and are available for immediate release once exocytosis is triggered by $\mathrm{Ca}^{2+}$ influx. Slower processes such as granule docking and priming become rate limiting during second phase of insulin secretion (Rorsman et al. 2000), and these were affected much less in the Shb knockout.

The expression profiles of genes related to specific $\beta$-cell function were not much changed in the $S h b$ knockout when compared with control islets. Only $P d x 1$ was significantly elevated, an effect that disappeared during culture, suggesting it to be a consequence of the disturbances in glucose homeostasis in the in vivo environment.

The microvasculature has recently been shown to play an important role for $\beta$-cell function (Johansson et al. 2006, Nikolova et al. 2006), and this prompted us to investigate the endothelial ultrastructure in SHB-deficient islets, especially, since we have recently observed a morphologically disordered endothelial phenotype in Shb knockout mice (Funa et al. 2009). As in liver and heart microvasculature, the islet endothelium exhibits aberrations. These show some similarities with those of the other organs, but differences are also noted. Whereas the islet endothelial cytoplasm was more voluminous as in the other organs, it showed fewer luminal extensions. There was also a decreased capillary density occurring concomitant with reduced gene expression of Vegf- $A$. The reduced vascular density indeed suggests that there is a diminished capacity of the islet microvasculature in the Shb knockout. Mice with pancreas or $\beta$-cell-specific Vegf- $A$ deletion (Lammert et al. 2003, Brissova et al. 2006, Iwashita et al. 2007) exhibit reduced islet capillary density and altered endothelial cell morphology, with reduced number of fenestrae, thick basement membrane and increased number of caveolae. Blood glucose tolerance was impaired and the in vivo insulin secretion was reduced (Brissova et al. 2006, Iwashita et al. 2007). In all, these mice exhibited more severe abnormalities than was observed in the present study, but it seems plausible that the altered vascularity in the $\operatorname{Shb}-/-$ islets influences glucose homeostasis in the $\mathrm{Sh} b-/-$ mice. The reduced insulin secretion from Shb-deficient isolated islets in batch incubation experiments suggests that reduced islet blood flow alone cannot explain the impaired $\beta$-cell function presently observed. However, reduced islet blood flow may be an indication of a dysfunctional endothelial compartment, a concept further reinforced by the morphological aberrations presently detected, and, consequently, supporting functions of endothelial cells on $\beta$-cells, as those on the common basement membrane or by local release of insulinotropic factors could be absent or reduced in the current situation (Johansson et al. 2006, Nikolova et al. 2006).

In summary, loss of the Shb gene impairs insulin secretion, alters the islet microvascular morphology, and leads to a slightly increased basal blood glucose concentration. We conclude from the present data that our model of genetic manipulation simultaneously affecting both $\beta$ - and endothelial cells, causes imbalances in function due to interference with the normal interactive processes occurring between these cell types.

\section{Declaration of interest}

The authors declare that there is no conflict of interest that could be perceived as prejudicing the impartiality of the research reported.

\section{Funding}

The study was supported by grants from the Juvenile Diabetes Research Foundation International (grant number 2005-945), the Swedish Research Council, the Swedish Diabetes Association, the Swedish Cancer Foundation, the Wallenberg Foundation, PO Zetterlings Stiftelse, and the Family Ernfors Fund.

\section{Author contribution statement}

$B \AA, S B, G C$, and D M performed the experiments and made the figures. B A, S B, L J, and M W wrote the manuscript. 


\section{Acknowledgements}

We are grateful to Birgitta Bodin, Astrid Nordin, Anders Ahlander, Eva Törnelius, Ing-Britt Hallgren, and Ing-Marie Mörsare for expert technical assistance.

\section{References}

Akerblom B, Anneren C \& Welsh M 2007 A role of FRK in regulation of embryonal pancreatic beta cell formation. Molecular and Cellular Endocrinology 270 73-78.

Anneren C \& Welsh M 2002 GTK tyrosine kinase-induced alteration of IRS-protein signalling in insulin producing cells. Molecular Medicine $\mathbf{8}$ 705-713.

Anneren C, Lindholm CK, Kriz V \& Welsh M 2003 The FRK/RAK-SHB signaling cascade: a versatile signal-transduction pathway that regulates cell survival, differentiation and proliferation. Current Molecular Medicine 3 313-324.

Barg S, Galvanovskis J, Gopel SO, Rorsman P \& Eliasson L 2000 Tight coupling between electrical activity and exocytosis in mouse glucagonsecreting alpha-cells. Diabetes 49 1500-1510.

Brissova M, Shostak A, Shiota M, Wiebe PO, Poffenberger G, Kantz J, Chen Z, Carr C, Jerome WG, Chen J et al. 2006 Pancreatic islet production of vascular endothelial growth factor - $\mathrm{a}$ is essential for islet vascularization, revascularization, and function. Diabetes 55 2974-2985.

Funa NS, Kriz V, Zang G, Calounova G, Akerblom B, Mares J, Larsson E, Sun Y, Betsholtz C \& Welsh M 2009 Dysfunctional microvasculature as a consequence of shb gene inactivation causes impaired tumor growth. Cancer Research 69 2141-2148.

Gerrish K, Cissell MA \& Stein R 2001 The role of hepatic nuclear factor 1 alpha and PDX-1 in transcriptional regulation of the pdx-1 gene. Journal of Biological Chemistry 276 47775-47784.

Gopel S, Kanno T, Barg S, Galvanovskis J \& Rorsman P 1999 Voltage-gated and resting membrane currents recorded from B-cells in intact mouse pancreatic islets. Journal of Physiology 521 717-728.

Holmqvist K, Cross MJ, Rolny C, Hagerkvist R, Rahimi N, Matsumoto T, Claesson-Welsh L \& Welsh M 2004 The adaptor protein shb binds to tyrosine 1175 in vascular endothelial growth factor (VEGF) receptor-2 and regulates VEGF-dependent cellular migration. Journal of Biological Chemistry 279 22267-22275.

Iwashita N, Uchida T, Choi JB, Azuma K, Ogihara T, Ferrara N, Gerber H, Kawamori R, Inoue M \& Watada H 2007 Impaired insulin secretion in vivo but enhanced insulin secretion from isolated islets in pancreatic beta cell-specific vascular endothelial growth factor-A knock-out mice. Diabetologia 50 380-389.

Jansson L 1986 Flow distribution between the endocrine and exocrine parts of the isolated rat pancreas during perfusion in vitro with different glucose concentrations. Acta Physiologica Scandinavica 126 533-538.
Jansson L \& Hellerstrom C 1981 A rapid method of visualizing the pancreatic islets for studies of islet capillary blood flow using non-radioactive microspheres. Acta Physiologica Scandinavica 113 371-374.

Johansson M, Mattsson G, Andersson A, Jansson L \& Carlsson PO 2006 Islet endothelial cells and pancreatic beta-cell proliferation: studies in vitro and during pregnancy in adult rats. Endocrinology 147 2315-2324.

Kriz V, Mares J, Wentzel P, Funa NS, Calounova G, Zhang XQ, Forsberg-Nilsson K, Forsberg M \& Welsh M 2007 Shb null allele is inherited with a transmission ratio distortion and causes reduced viability in utero. Developmental Dynamics 236 2485-2492.

Lammert E, Gu G, McLaughlin M, Brown D, Brekken R, Murtaugh LC, Gerber HP, Ferrara N \& Melton DA 2003 Role of VEGF-A in vascularization of pancreatic islets. Current Biology 13 1070-1074.

Lee CS, Sund NJ, Vatamaniuk MZ, Matschinsky FM, Stoffers DA \& Kaestner KH 2002 Foxa2 controls Pdx1 gene expression in pancreatic beta-cells in vivo. Diabetes 51 2546-2551.

Mokhtari D, Kerblom B, Mehmeti I, Wang X, Funa NS, Olerud J, Lenzen S, Welsh N \& Welsh M 2009 Increased Hsp70 expression attenuates cytokineinduced cell death in islets of Langerhans from Shb knockout mice. Biochemical and Biophysical Research Communications 387 553-557.

Nikolova G, Jabs N, Konstantinova I, Domogatskaya A, Tryggvason K, Sorokin L, Fassler R, Gu G, Gerber HP, Ferrara N et al. 2006 The vascular basement membrane: a niche for insulin gene expression and beta cell proliferation. Developmental Cell 10 397-405.

Rorsman P, Eliasson L, Renstrom E, Gromada J, Barg S \& Gopel S 2000 The cell physiology of biphasic insulin secretion. News in Physiological Sciences 15 72-77.

Velho G \& Robert JJ 2002 Maturity-onset diabetes of the young (MODY): genetic and clinical characteristics. Hormone Research $\mathbf{5 7}$ 29-33.

Welsh M, Mares J, Karlsson T, Lavergne C, Breant B \& Claesson-Welsh L 1994 Shb is a ubiquitously expressed Src homology 2 protein. Oncogene 9 19-27.

Welsh M, Christmansson L, Karlsson T, Sandler S \& Welsh N 1999 Transgenic mice expressing Shb adaptor protein under the control of rat insulin promoter exhibit altered viability of pancreatic islet cells. Molecular Medicine 5 169-180.

Welsh N, Makeeva N \& Welsh M 2002 Overexpression of the Shb SH2 domain-protein in insulin-producing cells leads to altered signaling through the IRS-1 and IRS-2 proteins. Molecular Medicine 8 695-704.

Received in final form 14 August 2009

Accepted 20 August 2009

Made available online as an Accepted Preprint 20 August 2009 